\title{
Concentration-dependent effects of fullerenol on cultured hippocampal neuron viability
}

This article was published in the following Dove Press journal:

International Journal of Nanomedicine

27 June 2012

Number of times this article has been viewed

\section{Ying-ying Zha' \\ Bo Yang' \\ Ming-liang Tang ${ }^{2}$ \\ Qiu-chen Guo' \\ Ju-tao Chen' \\ Long-ping Wen ${ }^{3}$ \\ Ming Wang'}

'CAS Key Laboratory of Brain Function and Disease, School of Life Sciences, University of Science and Technology of China, Hefei,

${ }^{2}$ Suzhou Institute of NanoTech and NanoBionics, Chinese Academy of Sciences, Suzhou, ${ }^{3}$ Laboratory of Nano-biology, School of Life Sciences, University of Science and Technology of China, Hefei, People's Republic of China
Correspondence: Ming Wang

School of Life Sciences, University of Science and Technology of China, Hefei, Anhui, 230027, People's Republic of China Tel +8655 I360 6374

Fax $+8655 \quad 1360 \quad 1443$

Email wming@ustc.edu.cn
Background: Recent studies have shown that the biological actions and toxicity of the water-soluble compound, polyhydroxyfullerene (fullerenol), are related to the concentrations present at a particular site of action. This study investigated the effects of different concentrations of fullerenol on cultured rat hippocampal neurons.

Methods and results: Fullerenol at low concentrations significantly enhanced hippocampal neuron viability as tested by MTT assay and Hoechst 33342/propidium iodide double stain detection. At high concentrations, fullerenol induced apoptosis confirmed by Comet assay and assessment of caspase proteins.

Conclusion: These findings suggest that fullerenol promotes cell death and protects against cell damage, depending on the concentration present. The concentration-dependent effects of fullerenol were mainly due to its influence on the reduction-oxidation pathway.

Keywords: fullerenol, nanomaterial, neurotoxicity, neuroprotection, hippocampal neuron

\section{Introduction}

Fullerene $\left(\mathrm{C}_{60}\right)$ has attracted great interest since it was discovered in soot by laser ablation of graphite in 1985. ${ }^{1}$ Fullerene represents a special group of compounds and has a number of applications due to its distinctive material properties. Its low solubility initially limited its use in biomedical science. ${ }^{2}$ This has now been overcome by the development of water-soluble suspensions of fullerenes. There is an increased interaction between linked hydrophilic functional groups on fullerenol molecule and water. Fullerene derivatives including fullerenol have become increasingly available for numerous applications. ${ }^{3}$

Fullerene and its derivatives have been found variously to have beneficial properties or harmful tendencies in many different fields of science. ${ }^{4}$ At low concentrations, fullerene and its derivatives might have a protective effect on cells or organs. It has been proposed that fullerene might play a role in treating drug abuse, because intraperitoneal administration of fullerene $100 \mathrm{mg} / \mathrm{kg}$ was found to prevent liver and kidney damage caused by morphine. ${ }^{5}$ In addition, intracerebroventricular administration of fullerene $0.3 \mathrm{mg} / \mathrm{kg}$ has been found to have a protective effect against ischemia-reperfusion injury. ${ }^{6}$ In other studies, intraperitoneal fullerene $10-100 \mathrm{mg} / \mathrm{kg}$ was found to prevent self-injurious behavior in mice, which might cause DNA and protein damage. ${ }^{7}$ Perhaps the most important property of fullerene derivatives is their ability to scavenge reactive oxygen species and free radicals. These properties were shown to be related to the antitumor effect observed after injection of $2 \times 10^{-7} \mathrm{~mol} / \mathrm{kg}\left[\mathrm{Gd} @ \mathrm{C}_{82}(\mathrm{OH})_{22}\right]_{\mathrm{n}}$ nanoparticles of fullerene to tumor-bearing mice. ${ }^{8}$ 
However, recent studies have raised concerns about their potential toxicity because, to a certain extent, the properties which preserve some biomedical functions may damage others. ${ }^{9}$ Generation of reactive oxygen species plays a critical role in this respect because it can result in damage to the cell membrane, lipid peroxidation, and necrotic cell death. Some scientists have suggested that hydroxylated fullerenes may be markedly less toxic than their parent compounds, but can still cause apoptosis at high concentrations. ${ }^{10}$ Hydroxylated fullerene at a concentration of $100 \mathrm{mg} / \mathrm{mL}$ was found to cause protein polyubiquitination in human umbilical vein endothelial cells, killed $58 \%$ of cells, and caused conspicuous leakage from the cell membrane. ${ }^{11}$ Other studies have shown that exposure of pregnant mice to fullerene $50 \mathrm{mg} / \mathrm{kg}$ resulted in placental transfer to the embryos and that maternal exposure to a higher dose $(137 \mathrm{mg} / \mathrm{kg})$ resulted in embryo death in all cases. ${ }^{12}$ The growing likelihood of accidental or inadvertent release of these substances into the environment calls for a better understanding of their properties, fate, and impact on biological systems.

In this paper, we focus on the concentration-dependent effects of fullerenol, a fullerene derivative, on cultured hippocampal neurons. Molecular dynamics have confirmed that fullerene derivatives have unusually high permeability into lipid membranes and are able to cross the blood-brain barrier. ${ }^{13,14}$ It has also been proposed that Buckminsterfullerene may have neuroprotective properties and cause lower glutamate receptor-induced elevation of $\mathrm{Ca}^{2+}$ levels..$^{15,16}$ These earlier studies suggest that the central nervous system may be a potential target of fullerene derivatives.

It has been shown that the toxicity of a nanomaterial can be approximately determined by more than ten factors and one of them is dose. ${ }^{17}$ The present study was undertaken to investigate the effects of different concentrations of fullerene on the central nervous system. We wanted to test if fullerenol at low concentrations had a repair function on lead-induced neuron damage in rats and if fullerenol at high concentrations induced neuronal apoptosis. We also analyzed the redox level of neurons exposed to different concentrations of fullerenol in order to determine its mechanism of action.

\section{Materials and methods Experimental animals}

Wistar rats were obtained from the Shanghai SLAC Laboratory Animal Center (Shanghai, China) and housed in the animal care facility at the University of Science and Technology of China. All rats were maintained according to the National Institute of Health Guidelines for the Care and Use of Laboratory Animals, and procedures for the care and use of rats were approved by the Animal Care Unit and Use Committee of the University of Science and Technology of China.

\section{Hippocampal neuron culture}

Hippocampal neurons were derived from newborn Wistar rats. Prior to culturing, 6-well plates (Costar, Cambridge, MA) were prepared for Comet assay, caspase- 3 and caspase- 9 activity assays, and measurement of oxidative stress; 24 -well plates (Costar) were prepared for Hoechst 33342/propidium iodide double stain detection; and 96-well plates (Costar) were prepared for MTT assay. The plates were precoated with $0.1 \mathrm{mg} / \mathrm{mL}$ of poly-L-lysine (Solarbio, Beijing, China).

Hippocampal tissue was dispersed at a cell density of $10^{4}-10^{5} / \mathrm{mL}$ in Dulbecco's Modified Eagle's Medium/F12 (DMEM/F12) medium (Gibco, Grand Island, NY) and 10\% fetal bovine serum (HyClone, Logan, UT). The suspension was incubated for $16-18$ hours at $37^{\circ} \mathrm{C}$ in $5 \% \mathrm{CO}_{2}$, and the cells were transferred into Neurobasal medium (Gibco) and $2 \%$ B27 supplement (Gibco) with glutamine $0.5 \%$ added. On day 3 , cytosine arabinoside $0.5 \%$ was added to the culture medium in order to arrest the growth of non-neurons. The neurons were cultured at $37^{\circ} \mathrm{C}$ in a $5 \% \mathrm{CO}_{2}$ incubator for 7 days, to obtain mature hippocampal neurons.

\section{Preparation of fullerenol}

Water-soluble polyhydroxyfullerene, obtained from MER Corporation (Tucson, AZ), was dissolved in Neurobasal medium. The resulting compound had the molecular formula $\mathrm{C}_{60}(\mathrm{OH})_{\mathrm{x}}(\mathrm{ONa})_{\mathrm{y}}(\mathrm{y} \approx 6-8, \mathrm{x}+\mathrm{y} \approx 24)$.

\section{Transmission electron microscopy imaging}

Field emission transmission electron microscopy imaging was performed on an FEI (Hillsboro, OR) Tecnai G2 F20 operated at $200 \mathrm{kV}$ to determine the physical properties of fullerenol at different concentrations.

\section{Neuron and astrocyte staining}

Cytosine arabinoside (Ara-C), which interferes with cell proliferation by inhibiting the cell DNA synthesis process, was added to the medium to arrest the growth of non-neuronal cells. Neurons and astrocytes were distinguished using mouse antineuronal nuclei monoclonal antibody (Chemicon, Temecula, CA), rabbit antiglial fibrillary acidic protein antibody (Chemicon), fluorescein isothiocyanate conjugate-goat antimouse IgG and tetramethylrhodamine isothiocyanate conjugate-goat antirabbit IgG. 


\section{Cell viability assay}

An MTT cell proliferation and cytotoxicity assay kit was purchased from Beyotime (Jiangsu, China). Concentrations of fullerenol ranged from $0 \mu \mathrm{M}$ to $100 \mu \mathrm{M}$. Hippocampal neurons were cultured in 96-well plates for 7 days and then exposed to fullerenol for 24,48 and 72 hours. A $200 \mu \mathrm{L}$ fresh medium sample was added to each well, together with $10 \mu \mathrm{L}$ of freshly prepared MTT $5 \mathrm{mg} / \mathrm{mL}$ and $100 \mu \mathrm{L}$ of dissolved formazan liquid. Absorbance was measured at $570 \mathrm{~nm}$ by a microplate reader.

\section{Hoechst 33342/propidium iodide detection}

Lead-induced damage was used to produce oxidative damage. In this study, a Hoechst 33342/propidium iodide detection kit from KeyGen BioTech (Nanjing, China) was used to measure the toxicity of lead in neurons and to assess the potential protective scavenging effects of fullerenol on the damage caused by lead exposure. It has been shown that lead significantly decreases hippocampal neuron survival at concentrations $>20 \mu \mathrm{M} .{ }^{18}$ Seven-day-old cells cultured in 24-well plates were exposed to lead at $20 \mu \mathrm{M}$ in the presence or absence of fullerenol for 24 and 48 hours. The cells were collected by enzymolysis and suspended $\left(10^{5}-10^{6}\right.$ cells) in $1 \mathrm{~mL}$ of medium to which $10 \mu \mathrm{L}$ Hoechst 33342 dye was added. The mixture was then left to react at $37^{\circ} \mathrm{C}$ for 10 minutes and was centrifuged at $1000 \mathrm{rpm}$ for 5 minutes at $4{ }^{\circ} \mathrm{C}$. The precipitate was mixed with $1 \mathrm{~mL}$ of buffer and $5 \mu \mathrm{L}$ of propidium iodide dye for 10 minutes at room temperature. Fluorescence was measured at $352 \mathrm{~nm}$ and $488 \mathrm{~nm}$ (excitation wavelength) using a microscope (Zeiss, Oberkochen, Germany).

\section{Comet assay}

The extent of cell damage from exposure to high concentrations $(50,100$, and $200 \mu \mathrm{M})$ of fullerenol was assessed. Neurobasal medium (control) or fullerenol was added to the cells which have been cultured for 7 days. After 24 or 48 hours, a suspension of neurons was mixed 1 to 1 with molten lowmelting-point agarose at $37^{\circ} \mathrm{C}$ and was spread onto a glass microscope slide. Individual cells were embedded in a thin agarose gel on a clean slide, and the DNA was allowed to unwind in the dark under alkaline conditions for one hour at $4^{\circ} \mathrm{C}$. DNA electrophoresis was undertaken at $25 \mathrm{~V}$ for 25 minutes at $4^{\circ} \mathrm{C}$, allowing the broken DNA fragments and damaged DNA to migrate away from the nucleus. The reaction mixture was then neutralized and washed three times with 0.4 $\mathrm{M}$ Tris- $\mathrm{HCl}(\mathrm{pH}$ 7.5). The neurons were stained with a DNA- specific fluorescent dye such as ethidium bromide. Using this technique the resulting images resemble a "comet" with a distinct head and tail. The size of the comet and the distribution of DNA correlate with the extent of DNA damage. ${ }^{19}$

\section{Caspase- 3 and caspase- 9 activity}

Caspase- 9 and caspase- 3 activity assay kits (Beyotime) were used to validate generation and to find the possible pathway for apoptosis. Cells cultured for 7 days were exposed for 24 hours to fullerenol 50,100, or $200 \mu \mathrm{M}$. The broken cells were collected and washed. The homogenate was centrifuged at $16,000 \mathrm{rpm}$ for 20 minutes at $4^{\circ} \mathrm{C}$, and the supernatant was used or stored at $-80^{\circ} \mathrm{C}$. A reaction mixture containing $50 \mu \mathrm{L}$ of detection buffer liquid, $40 \mu \mathrm{L}$ samples, and $10 \mu \mathrm{L}$ Ac-DEVD- $p$ NA ( $2 \mathrm{mM}$ ), was incubated for 120 minutes at $37^{\circ} \mathrm{C}$. Absorbance was recorded at $405 \mathrm{~nm}$ on a microplate reader (Ex1800; BioTek, Seattle, WA).

\section{Measurement of oxidative stress}

Assay kits obtained from Nanjing Jiancheng Bioengineering Institute (Nanjing, China) were used to measure superoxide dismutase (SOD) activity, glutathione (GSH) levels, and maleic dialdehyde (MDA) concentrations. Cells cultured in 6-well plates for 7 days were exposed to fullerenol for 24 hours. Neurons were collected, centrifuged at 16,000 rpm for 20 minutes at $4^{\circ} \mathrm{C}$, and the supernatant was collected to provide samples for assay.

SOD reagent was added to $0.2 \mathrm{~mL}$ samples to assess whether removal of superoxide anions protected cells from damage. The reaction mixture contained $1.2 \mathrm{~mL}$ of sodium pyrophosphate buffer $0.052 \mathrm{mM}(\mathrm{pH} 7.0), 0.1 \mathrm{~mL}$ of phenazine methosulfate $186 \mu \mathrm{M}$, and $0.3 \mathrm{~mL}$ of nitro blue tetrazolium $300 \mu \mathrm{M} .{ }^{18}$ Absorbance was measured at $550 \mathrm{~nm}$.

GSH reagent containing 5,5-dithiobes-2-ni-trobenzoic acid was mixed with $0.1 \mathrm{~mL}$ of the assay sample for 5 minutes to assess molecular clearance and oxidation resistance. The optical density value was obtained at an absorbency of $405 \mathrm{~nm}$.

MDA assay to evaluate the extent of cell damage involved exposing $0.1 \mathrm{~mL}$ of the sample to thiobarbituric acid at $95^{\circ} \mathrm{C}$ for 40 minutes. The heated supernatant was cooled with running water and absorbance at $532 \mathrm{~nm}$ was recorded on a spectrophotometer.

\section{Data analysis}

Data were collected using Image-Pro Plus 6.0 (Media Cybernetics, Bethesda, MD) for the Hoechst 33342/propidium 
iodide assay and CASP 1.2.2 (University of Wroclaw) for the Comet assay. Data were analyzed using Origin 8.0 software (University of Northampton, Northampton, MA). Values were expressed as the mean \pm standard error. One-way analysis of variance and Tukey tests were used to identify treatment differences. Values of $P<0.05$ were to be considered statistically significant.

\section{Results}

\section{Characterization of fullerenol}

Because the culture medium composition was too complex to enable electron microscopy to be undertaken, the molecular structure of fullerenol was observed after dissolution in water. As shown in Figure 1A and B, fullerenol at a low concentration $(1 \mu \mathrm{M})$ appeared as a monomer in water, and in Figure $1 \mathrm{C}$ and $\mathrm{D}$, at the highest concentration used in our experiments $(200 \mu \mathrm{M})$, it was also predominantly in the monomer form with only a small amount of aggregation seen.

\section{Neuronal and astrocyte differentiation}

Figure 2 shows the effects of Ara-C on astrocyte and neuron cell numbers. Administration of Ara-C interfered with astrocyte growth by arresting cell proliferation. In Figure 2E, astrocytes accounted for $49.6 \%$ of the cultured cells prior to Ara-C administration but accounted for only $8.2 \%$ of cells after exposure to Ara-C.

\section{Effects of fullerenol on neuron viability based on concentration}

Cell viability was measured in order to estimate the effect of fullerenol on cultured hippocampal neurons. As shown in Figure 3A, exposure to fullerenol for 24 hours at concentrations of $1 \mu \mathrm{M}$ and $5 \mu \mathrm{M}$ increased hippocampal neuron viability by $111.55 \% \pm 0.53 \%(P<0.01)$ and $110.33 \% \pm 1.82 \%$ $(P<0.05)$, respectively. Fullerenol at concentrations $>5 \mu \mathrm{M}$ had no effect on cell viability. In Figure 3B, exposure of cells to fullerenol $100 \mu \mathrm{M}$ for 48 hours reduced neuron viability to

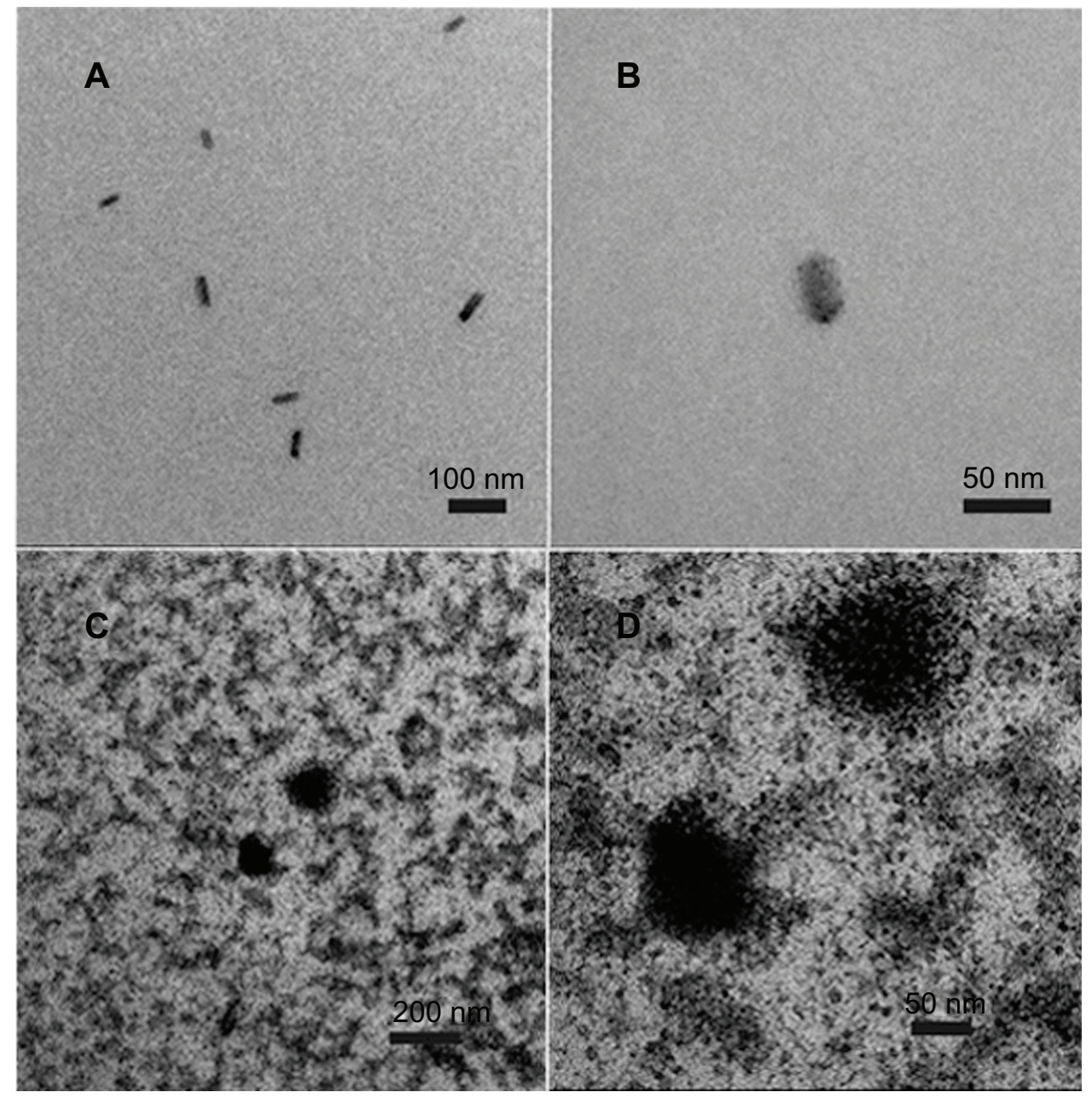

Figure I Transmission electron microscopy image of the physical state of $\mathrm{C}_{60}(\mathrm{OH})_{x}(\mathrm{ONa})_{y^{*}}(\mathbf{A})$ Image of I $\mu \mathrm{M}$ fullerenol in water. (B) Amplified image of I $\mu \mathrm{M}$ fullerenol in water. (C) Image of $200 \mu \mathrm{M}$ fullerenol in water. (D) Amplified image of $200 \mu \mathrm{M}$ fullerenol in water. 

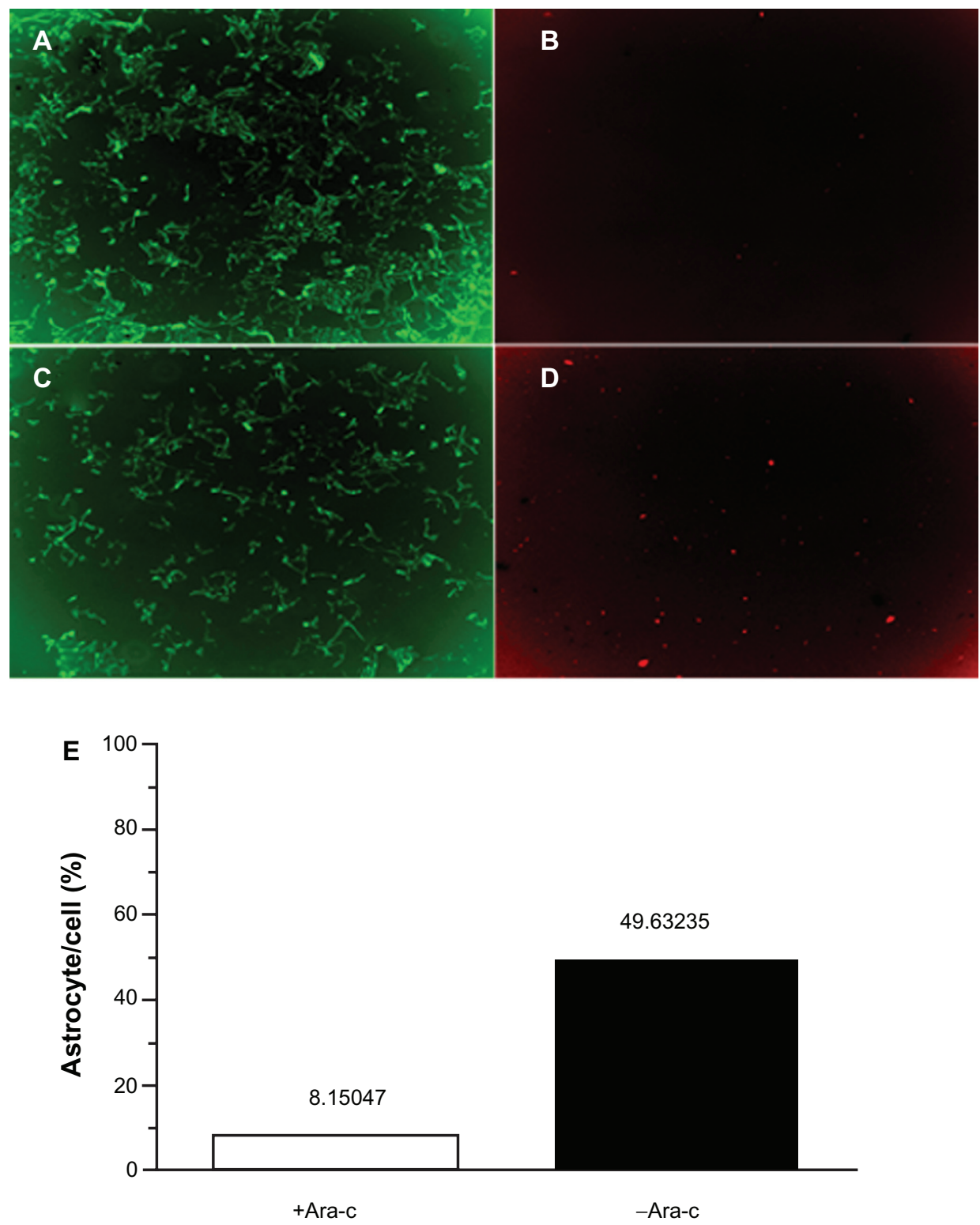

Figure 2 Double staining of neurons and astrocytes. (A) Neurons in the + Ara-C group. (B) Astrocytes in the + Ara-C group. (C) Neurons in the - Ara-C group. (D) Astrocytes in the -Ara-C group. (E) Histogram showing the ratio of astrocyte to cell numbers.

Abbreviation: Ara-C, cytosine arabinoside.

$89.62 \% \pm 2.90 \%(P<0.01)$, whereas no significant changes were seen at concentrations $<25 \mu \mathrm{M}$. Exposure of cells to fullerenol $25 \mu \mathrm{M}$ and $100 \mu \mathrm{M}$ for 72 hours (Figure 3C) reduced neuron viability to $83.59 \% \pm 2.26 \%(P<0.01)$ and $84.21 \% \pm 2.45 \%(P<0.01)$, respectively.

\section{Effect of fullerenol on lead-induced hippocampal neuronal damage}

The possible protective effect of fullerenol against leadinduced cytotoxicity was assessed by Hoechst/propidium iodide assay. Hoechst dye entered into living cells, producing blue fluorescence, and propidium iodide dye entered into dead cells, producing red fluorescence. Figure $4 \mathrm{~A}$ shows three bright-field images detected with a high-power optical microscope. The left image shows normal cells; the middle image shows necrotic cell after exposure to lead; and the right image shows partially viable cells exposed to lead and to fullerenol. Propidium iodide fluorescence intensity increased in cells exposed to lead, whereas no notable change was seen after exposure to lead and fullerenol (Figure 4B). Figure 4C and D show the effect of fullerenol on hippocampal neuron survival rate after exposure to lead. Survival was reduced after exposure to lead acetate for 24 hours $(82.61 \% \pm 5.84 \% ; P<0.01)$ or 48 hours $(72.52 \% \pm 5.49 \% ; P<0.01)$. Concurrent exposure to 

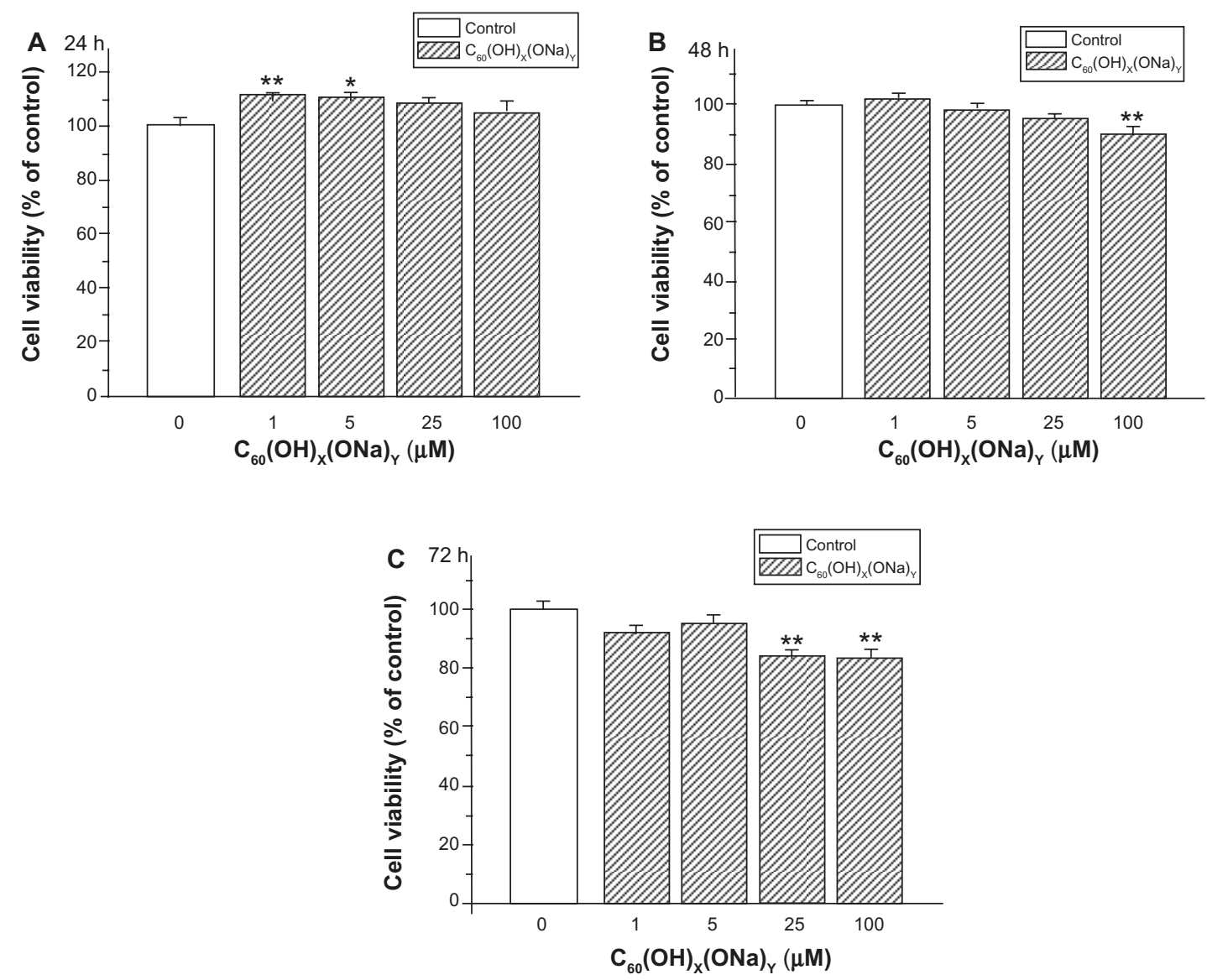

Figure 3 Effect of $\mathrm{C}_{60}(\mathrm{OH})_{x}(\mathrm{ONa})_{y}$ on viability of cultured hippocampal neurons. (A) Hippocampal neurons treated with fullerenol 0 , I, 5 , 25 , and I00 $\mu \mathrm{M}$ for 24 hours. (B) Hippocampal neurons treated for 48 hours. (C) Hippocampal neurons treated for 72 hours.

Notes: The results show mean \pm standard error $(n=8)$ values from a representative experiment that was repeated at least three times. $* P<0.05$ versus control group; $* * P<0.01$, versus control group. One-way analysis of variance with Bonferroni post hoc tests.

Abbreviation: Pl, propidium iodide.

fullerenol provided significant protection against lead-induced neurotoxicity. After exposure for 24 hours to fullerenol 1,5 , and $25 \mu \mathrm{M}$, cell viability was, respectively, increased $95.87 \% \pm 1.29 \%(P<0.05), 97.93 \% \pm 0.92 \%(P<0.01)$, and $95.55 \% \pm 2.05 \%(P<0.05)$ of control values. However, this protective effect becomes inconspicuous in Figure 4D.

\section{Influence of high concentrations of fullerenol in Comet assays}

The influence of fullerenol at high concentrations on hippocampal neuronal apoptosis is shown in Figure 5. A normal cell comprises a single head (Figure 5A) while an apoptotic cell has both a head and a long tail (Figure 5B). In analytic, images normal cells are characterized by one peak and apoptotic cells by two peaks. Figure $5 \mathrm{C}$ shows mean percentage changes in DNA. Following exposure to fullerenol $50 \mu \mathrm{M}$ for 24 hours, there was no notable change in the mean percentage of tail DNA relative to the control group; however, DNA content increased at concentrations $>100 \mu \mathrm{M}$. The mean
DNA content also increased after exposure for 48 hours. After exposure for 24 hours, the DNA content was $2.01 \% \pm 0.36 \%$ in the control group and $17.88 \% \pm 1.76 \%$ in the $200 \mu \mathrm{M}$ group $(P<0.01)$. Corresponding values after 48 hours of exposure were $2.65 \% \pm 0.46 \%$ and $28.20 \% \pm 2.74 \%$, respectively $(P<0.01)$. As shown in Figure 5D, there was evidence of a positive association between the numerical value of the olive tail moment and concentration of fullerenol. In the control group, all values were $<1$ or $<5$, whereas in the group exposed to fullerenol $200 \mu \mathrm{M}$ for 48 hours, some values were $>10$ or $>20$.

\section{Changes in caspase protein content in hippocampal neurons}

Compared with control neurons, there were no significant changes in caspase protein in the $50 \mu \mathrm{M}$ group, whereas neurons exposed to fullerenol $100 \mu \mathrm{M}$ or $200 \mu \mathrm{M}$ for 24 hours had significantly increased caspase-3 activity (Figure 6A) and caspase-9 activity (Figure 6B). Exposure to fullerenol $100 \mu \mathrm{M}$ and 
A
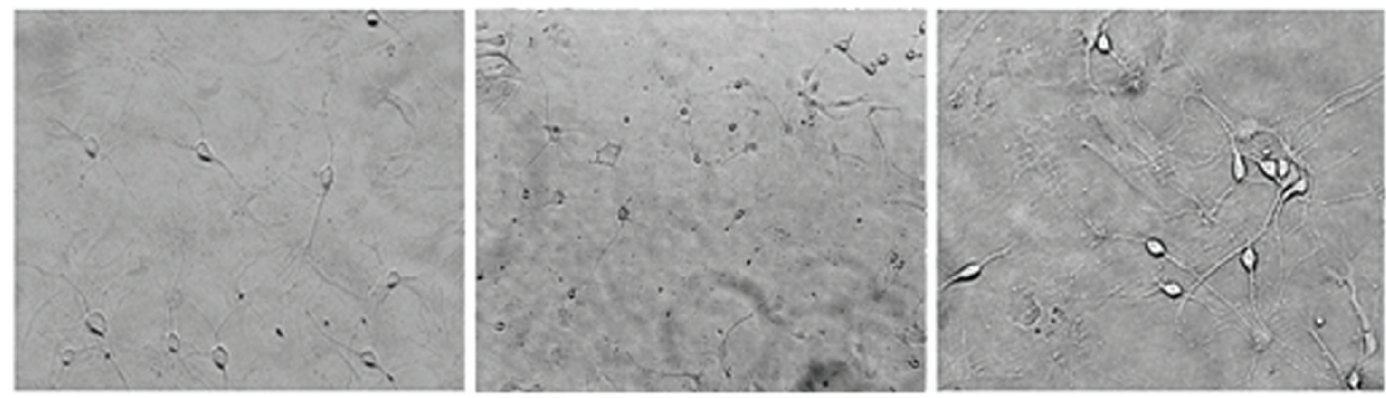

B Hoechst
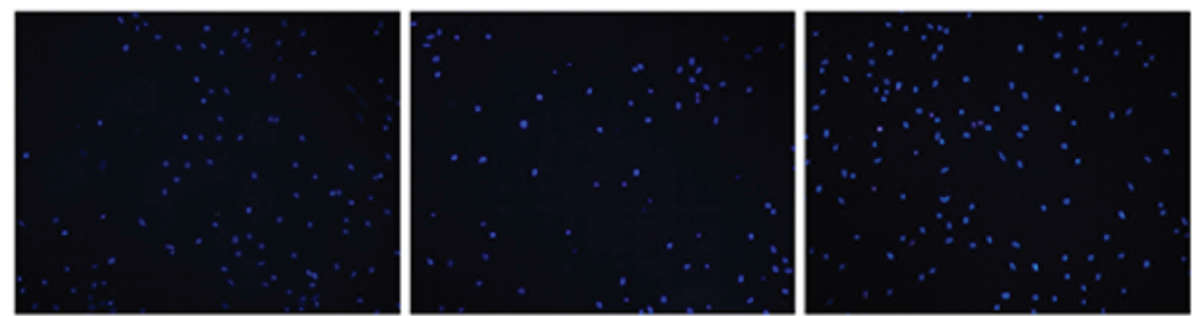

$\mathrm{PI}$
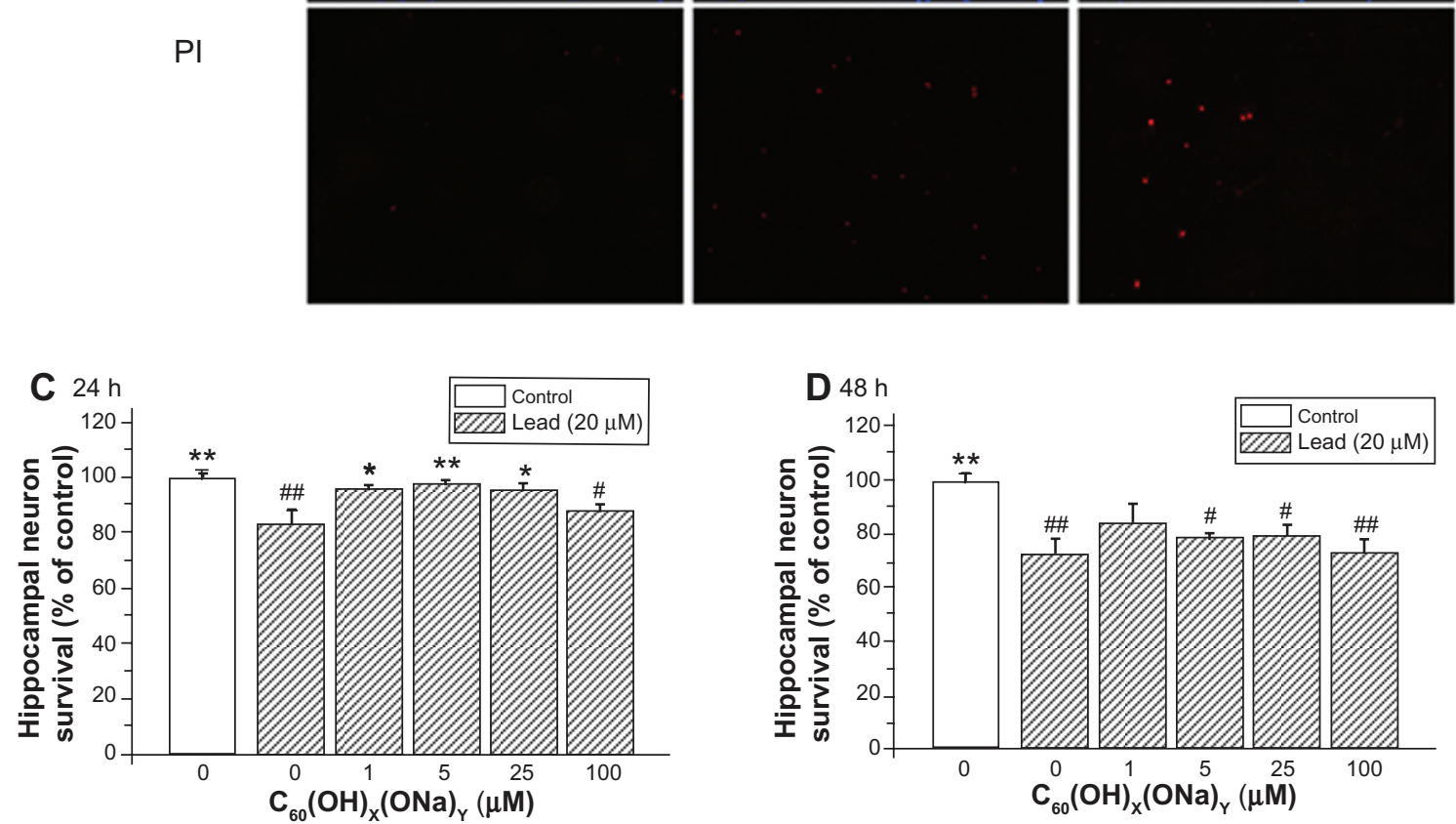

Figure 4 Protective effect of $\mathrm{C}_{60}(\mathrm{OH})_{x}(\mathrm{ONa})_{y}$ against lead-induced neurotoxicity. Hippocampal neurons were treated with various concentrations of fullerenol 0 , I, 5, 25, and $100 \mu \mathrm{M}$ and lead $20 \mu \mathrm{M}$ for 24 or 48 hours. The Hoechst dye entered into normal cells and emitted blue fluorescence, while the propidium iodide dye entered into necrotic cells and emitted red fluorescence. (A) Three typical images of random fields per treatment group detected with a high-power optical microscope. Left, control; middle, $20 \mu \mathrm{M}$ lead-exposed for 24 hours; right, $20 \mu \mathrm{M}$ lead and I $\mu \mathrm{M}$ fullerenol exposed for 24 hours. Magnification is I0 $\times 20$. (B) Three typical images detected with fluorescence microscopy. (C) Survival rate of hippocampal neurons after coculturing for 24 hours. (D) Survival rate after coculturing for 48 hours.

Notes: $* P<0.05$ versus lead-exposed group without fullerenol. $* * P<0.01$ versus lead-exposed group without fullerenol. $\# P<0.05$ versus control group; $\# P<0.01$ versus control group. One-way analysis of variance with the Bonferroni post hoc tests.

$200 \mu \mathrm{M}$, respectively, increased caspase- 3 to $130.24 \% \pm 4.77 \%$ and $150.77 \% \pm 7.10 \%$ (both $P<0.01$ ) of control levels. Corresponding values for caspase-9 were $128.67 \% \pm 2.34 \%$ and $136.23 \% \pm 1.11 \%$, respectively (both $P<0.01$ ).

\section{SOD, GSH, and MDA activity in hippocampal neurons}

Figure 7A shows that the activity of SOD significantly increased from $121.91 \pm 1.57 \mathrm{U} / \mathrm{mprot}$ in the control group to $152.98 \pm 1.60 \mathrm{U} / \mathrm{mprot}(P<0.01)$ in cells exposed to fullerenol $1 \mu \mathrm{M}$. In the $100 \mu \mathrm{M}$ group, there was a significant decrease to $88.09 \pm 0.61 \mathrm{U} / \mathrm{mprot}$, respectively $(P<0.01)$. There were no notable changes in the $5 \mu \mathrm{M}$ and $25 \mu \mathrm{M}$ groups. As shown in Figure 7B, there was a significant increase in GSH from $0.92 \pm 0.13 \mathrm{mg} /$ gprot in controls to $2.10 \pm 0.40 \mathrm{mg} /$ gprot after exposure to fullerenol $5 \mu \mathrm{M}$ $(P<0.05)$, and there was a decline in GSH with fullerenol at $100 \mu \mathrm{M}(0.92 \pm 0.15 \mathrm{mg} /$ gprot $)$. In Figure 7C, MDA 

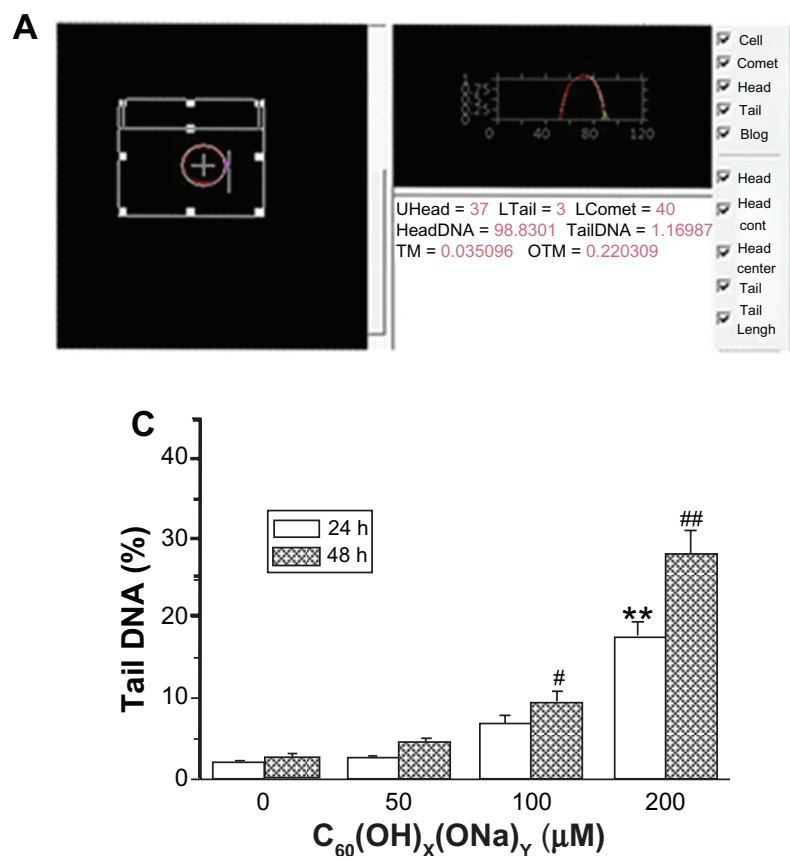

B
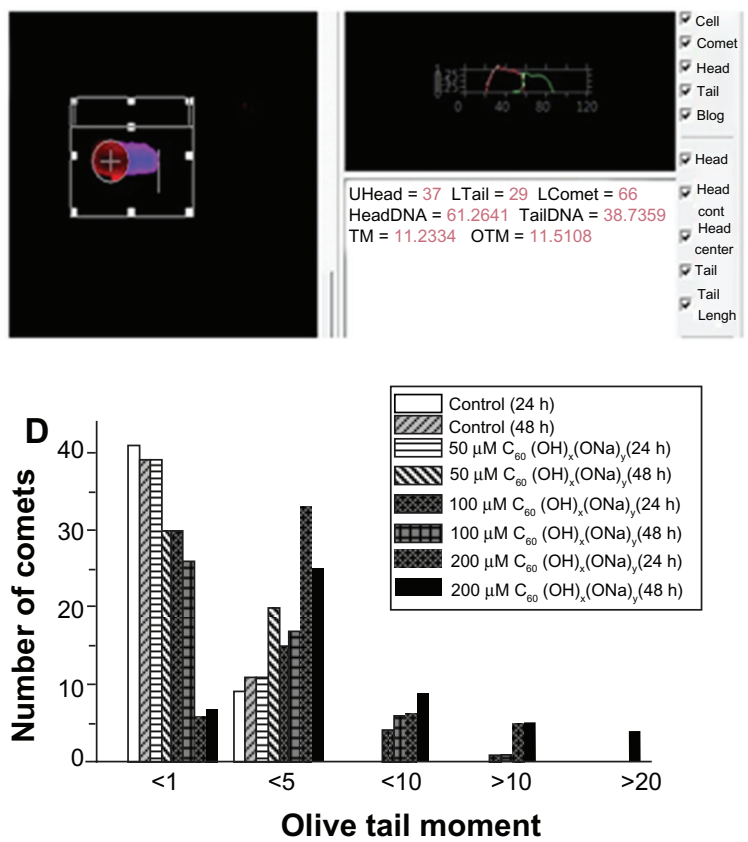

Figure 5 High concentrations of $\mathrm{C}_{60}(\mathrm{OH})_{x}(\mathrm{ONa})_{y}$ can induce apoptosis. (A) Comet image of a normal neuron detected with CASP software. (B) Comet image of an apoptosis neuron. (C) Mean percentage of tail DNA in hippocampal neurons treated with fullerenol 0, 50, 100, and 200 $\mu$ M. (D) Olive tail moment distribution (50 observations) in hippocampal neurons treated with fullerenol 0, 50, 100, and $200 \mu \mathrm{M}$.

Notes: The results are shown as the mean \pm standard error $(n=50)$ of a representative experiment that was repeated at least three times. **P $<0.01$ versus control group in 24 hours. ${ }^{\#}<0.05$ versus control group in 48 hours; ${ }^{\#} P<0.01$ versus control group in 48 hours. One-way analysis of variance with Bonferroni post hoc tests.

levels showed no significant decrease from control values (2.03 $\pm 0.01 \mathrm{mg} / \mathrm{gprot})$ after exposure to $5 \mu \mathrm{M}$ fullerenol $(1.85 \pm 0.11 \mathrm{mg} / \mathrm{gprot})$ and no significant increase after exposure to fullerenol $100 \mu \mathrm{M}(2.15 \pm 0.04 \mathrm{mg} /$ gprot $)$.

\section{Discussion}

Our own extensive experience and study of the mechanism of lead poisoning has shown that its effects are not readily reversed. It has been reported that cell damage following exposure to lead is caused by oxidative damage. ${ }^{20}$ For these reasons, we chose lead toxicity for our current experiments in order to investigate whether fullerenol had the ability to restore oxidative damage, or whether it induced oxidative damage in itself. Our results show that, at low concentrations, fullerenol significantly increased hippocampal neuronal viability and protected neurons from oxidative damage, improving the survival rate of cells exposed to lead. However, at high concentrations, fullerenol decreased
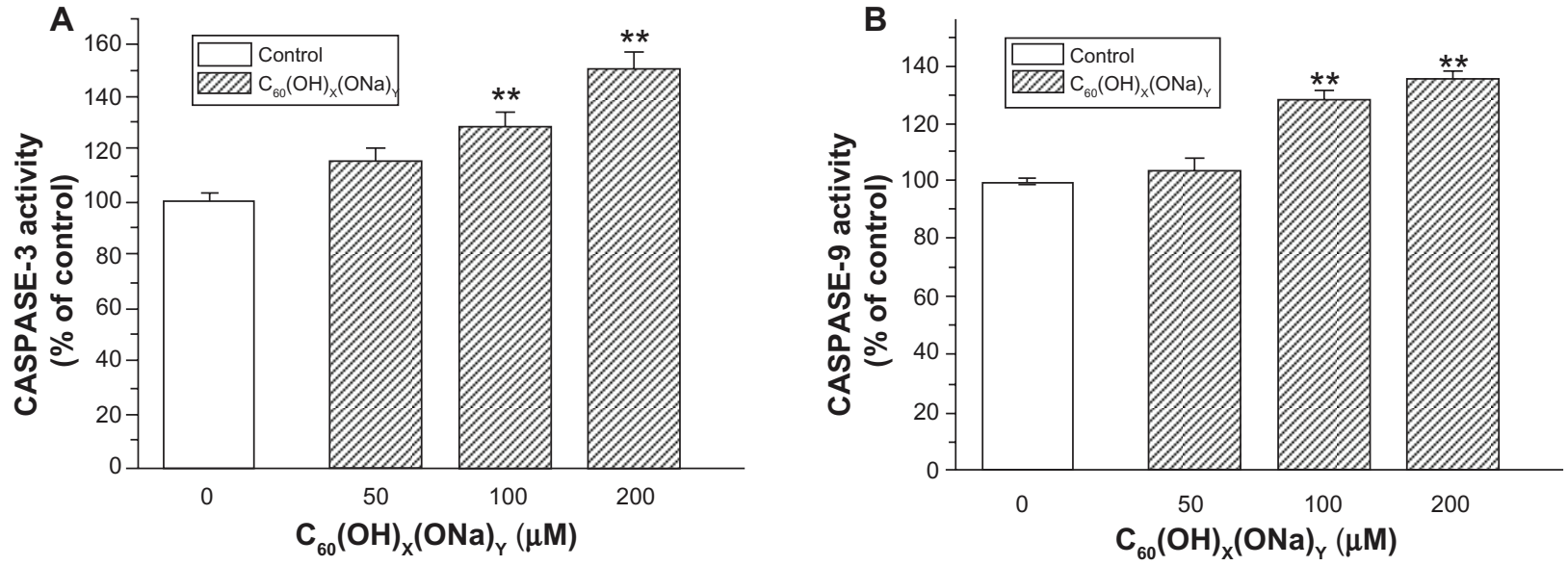

Figure 6 Effect of $\mathrm{C}_{60}(\mathrm{OH})_{x}(\mathrm{ONa})_{y}$ on caspase content of cultured hippocampal neurons. Hippocampal neurons were treated with fullerenol 0 , 50 , 100 , and $200 \mu \mathrm{M}$ for 24 hours. (A) Caspase-3 activity was detected using a protein assay kit. (B) Caspase- 9 activity was detected.

Notes: The results are the mean \pm standard error $(n=8)$ of a representative experiment that was repeated at least three times. $* * P<0.01$ versus control group. One-way analysis of variance with Bonferroni post hoc tests. 

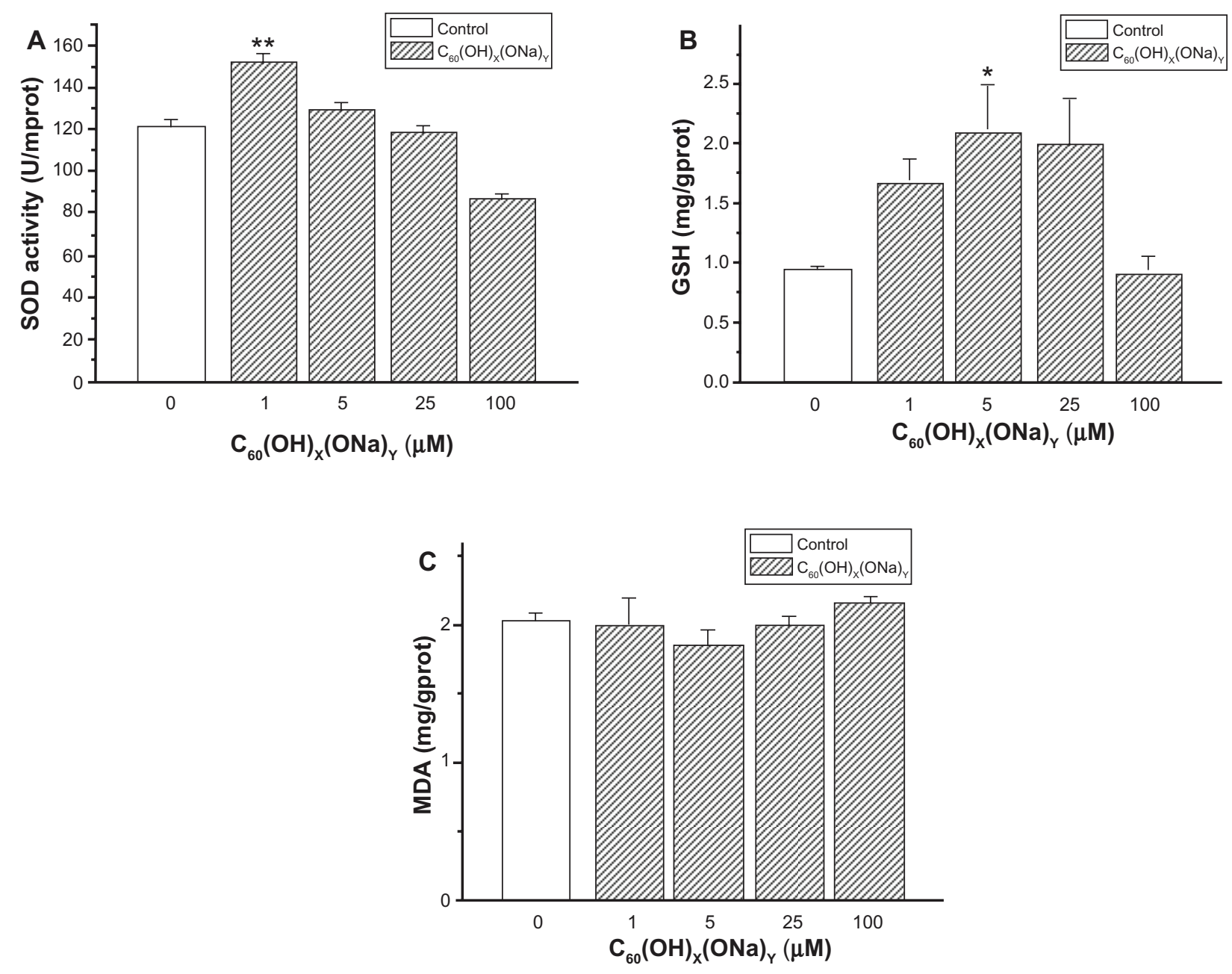

Figure 7 Extent of oxidative stress in cultured hippocampal neurons of control and fullerenol-exposed groups (I, 5, 25, and I00 $\mu \mathrm{M})$. (A) Effects of fullerenol on superoxide dismutase activity in cultured hippocampal neurons. (B) Effects of fullerenol on glutathione level in neurons. (C) Effects of fullerenol on maleic dialdehyde content in neurons. Notes: Values are mean \pm standard error $(n=26)$. $* P<0.05$ versus corresponding value of control group; **P $<0.0$ I versus corresponding value of control group. One-way analysis of variance with the Bonferroni post hoc tests.

Abbreviations: GSH, glutathione; MDA, maleic dialdehyde; SOD, superoxide dismutase.

hippocampal neuron viability and induced apoptosis. These findings support the notion that water-soluble fullerene may be an effective agent against lead poisoning with an antioxidant mechanism, and appears to be involved in the process of apoptosis caused by mitochondrial damage.

The first finding of our study was that low concentrations of fullerenol significantly increased the viability of cultured hippocampal neurons. Cell viability was assessed by MTT assay, which measures cell proliferation rate by measuring reduction in mitochondria. As neurons cannot proliferate or regenerate, increased cell viability indicates enhancement of reducing power. It is interesting in this context to note that treatment with e,e,e- $\mathrm{C}_{60}\left(\mathrm{C}(\mathrm{COOH})_{2}\right)_{3}$ has been shown to reduce superoxide radical formation in brain mitochondria and increase the lifespan of mice. ${ }^{14}$ Fullerenol is known to have scavenging ability, but the role of this property remains unknown. Our data from Hoechst 33342/propidium iodide detection studies indicate that fullerenol is able to increase the survival neurons exposed to lead and, therefore, suggest that fullerenol might protect neurons against lead-induced damage.

Another significant finding of our study was that fullerenol at high concentrations decreased the viability of cultured hippocampal neurons. Other studies have shown that, at high concentrations, the toxicity of fullerene derivatives induces apoptosis..$^{10}$ Our findings support this hypothesis in part. Using Comet assays, we found evidence of apoptosis in hippocampal neurons exposed to high concentrations of fullerenol. In our experiments, the magnitude of tail DNA in experimental groups changed according to length of exposure and concentration, and numerical values for the olive tail moment were also characteristic of apoptosis.

Caspases are a family of proteases that plays an important role in the process of apoptosis. These agents selectively 
remove specific peptide bonds and thereby promote apoptosis. Some caspases, such as caspase-9, act as initiators, and are activated by foreign protein signals to remove downstream proteins. Other caspases, such as caspase-3, induce apoptosis by hydrolyzing target proteins. In our experiments, we identified both caspase- 9 and caspase- 3 . Caspase-9 is linked to the mitochondrial death pathway, and caspase-3 interacts with caspase- 9 and some other caspases. Therefore, the concentrations of caspase- 3 and caspase- 9 proteins are an important index of apoptosis induced through the cytochrome-c signaling pathway. An elevation of both caspases as was apparent in our experiments, suggests that apoptosis is related to mitochondrial damage.

The ability of fullerenol to increase cell viability in MTT experiments may be the consequence of increased reduction reactions within neurons. We consider the increasing of cell viability to be the enhancement of reducing power. The Hoechst 33342/propidium iodide double stain detection experiments suggest that reduction reactions ease oxidative stress. We propose that at low concentrations fullerenol increases reducing power and thereby enhances hippocampal neuron viability and improves survival rate in the leadexposed groups. The Comet and caspase- 3 and caspase- 9 assays suggest that the mean percentage of tail DNA and the content of caspase protein in cultured hippocampal neurons both increase in oxidant-induced apoptosis. Thus, at high concentrations, fullerenol may increase oxidative stress and induce apoptosis via the caspase-9 pathway. To prove these points, we tested SOD, GSH, and MDA levels. SOD is a critical component of the oxidant defense system, and in our experiments its levels showed a significant decrease. GSH, a molecular clearing agent, increased at low concentrations of fullerenol and decreased at high concentrations. MDA levels, which are an index of lipid peroxidation, decreased at low concentrations and increased at high concentrations of fullerenol. These finding suggest that there was an increase in reduction reactions in neurons at lower concentrations of fullerenol, and that there was increasing oxidative stress in neurons with higher concentrations of fullerenol. Based on these findings, we propose that the fate of neurons depends on the redox level within neurons, and this in turn depends on the concentration of fullerenol that they are exposed to.

In our experiments, we used transmission electron microscopy to detect the physical state of fullerenol at different concentrations. Other workers have shown that fullerenol is present as a monomer state at concentration of $<4 \times 10^{-5}$ $\mathrm{M}$ and as an aggregate state at concentrations $>2 \times 10^{-4} \mathrm{M}^{21}$ Our transmission electron microscopic imaging studies showed that, at lower concentrations, the compound was in the form of monomer in water, and at higher concentrations, both monomer and aggregate states were found. Thus we have demonstrated that at lower concentrations fullerenol in the monomer state protected neurons against oxidative stress, and at higher concentrations, fullerenol in both monomer and aggregate states induced oxidant-induced apoptosis. Hydroxyl groups attached to the fullerene core might contribute to free radical scavenging, while aggregates might cause oxidative damage. Thus, one of the reasons for the redox level changes might be the state of fullerenol.

Our current findings have some practical significance for human life. Due to their special material and bonding properties, fullerenes have found a use not only in a range of technologies, and also in living systems. ${ }^{22} \mathrm{~A}$ recent study using fluorescence analysis showed that water-soluble fullerenol was able to destroy amyloid fibrils of the brain peptide Abeta (1-42) in vitro and had a potential role in treating Alzheimer disease. ${ }^{23}$ Other reports indeed have paid more attention to studies in vivo. For instance, it has been shown that fullerene altered the vertical migration response of Daphnia magna to the addition of food, and reduced swimming speed. ${ }^{24}$

In summary, our study has clearly shown that fullerenol can be deemed a promoter of cell death as well as a protector against oxidative risk, depending on the concentration used. Further in vivo and in vitro studies are needed to understand better the underlying mechanisms of these dual effects. Because of their growing uses, nanoparticles are widely regarded as new types of chemical pollutants. ${ }^{25}$ Recent air samples from urban atmospheres have been shown to contain fullerene and its derivatives, demonstrating that humans are exposed to environmental fullerene and its derivatives via inhalation. ${ }^{26}$ The increasing use of fullerene materials therefore warrants toxicological investigation.

\section{Acknowledgment}

This work was supported by The National Nature Science Foundation of China (31170965, 30630057), Chinese Ministry of Sciences 973 Program (2012CB932502), and the Fundamental Research Funds for the Central Universities (WK2070000002, 2070000004, 2070000008).

\section{Disclosure}

The authors report no conflicts of interest in this work.

\section{References}

1. Kroto HW, Heath JR, O'Brien SC, Curl RF, Smalley RE. $\mathrm{C}_{60}$ : buckminsterfullerene. Nature. 1985;318:162-163.

2. Djordjevic A, Bogdanovic G, Dobric S. Fullerenes in biomedicine. J BUON. 2006;11:391-404. 
3. Li D, Fortner JD, Johnson DR, Li Q, Alvarez PJ. Bioaccumulation of $14 \mathrm{C}_{60}$ by the earthworm Eisenia fetida. Environ Sci Technol. 2010;44:9170-9175.

4. Nielsen GD, Roursgaard M, Jensen KE, Poulsen SS, Larsen ST. In vivo biology and toxicology of fullerenes and their derivatives. Basic Clin Pharmacol Toxicol. 2008;103:197-208.

5. Mori T, Ito S, Kita T, et al. Involvement of free radicals followed by the activation of phospholipase $\mathrm{A}(2)$ in the mechanism that underlies the combined effects of methamphetamine and morphine on subacute toxicity or lethality in mice: comparison of the therapeutic potential of fullerene, mepacrine, and cooling. Toxicology. 2007;236:149-157.

6. Lin AMY, Fang SF, Lin SZ, Chou CK, Luh TY, Ho LT. Local carboxyfullerene protects cortical infarction in rat brain. Neurosci Res. 2002;43:317-321.

7. Mori T, Ito S, Kita T, et al. Oxidative stress in methamphetamine-induced self-injurious behavior in mice. Behav Pharmacol. 2007;18:239-249.

8. Wang J, Chen C, Li B, et al. Antioxidative function and biodistribution of $\left[\mathrm{Gd} @ \mathrm{C}_{82}(\mathrm{OH})_{22}\right]_{\mathrm{n}}$ nanoparticles in tumor-bearing mice. Biochem Pharmacol. 2006;71:872-881.

9. Oberdorster E. Manufactured nanomaterials (fullerenes, $\mathrm{C}_{60}$ ) induce oxidative stress in the brain of juvenile largemouth bass. Environ Health Perspect. 2004;112:1058-1062.

10. Isakovic A, Markovic Z, Todorovic-Markovic B, et al. Distinct cytotoxic mechanisms of pristine versus hydroxylated fullerene. Toxicol Sci. 2006;91:173-183.

11. Yamawaki H, Iwai N. Cytotoxicity of water-soluble fullerene in vascular endothelial cells. Am J Physiol Cell Physiol. 2006;290:1495-1520.

12. Tsuchiya T, Oguri I, Yamakoshi YN, Miyata N. Novel harmful effects of fullerene on mouse embryos in vitro and in vivo. FEBS Lett. 1996; 393:139-145.

13. Bedrov D, Smith GD, Davande H, LW Li. Passive transport of $\mathrm{C}_{60}$ fullerenes through a lipid membrane: a molecular dynamics simulation study. J Phys Chem B. 2008;112:2078-2084.

14. Quick KL, Ali SS, Arch R, Xiong C, Wozniak D, Dugan LL. A carboxyfullerene SOD mimetic improves cognition and extends the lifespan of mice. Neurobiol Aging. 2008;29:117-128.
15. Dugan LL, Gabrielsen JK, Yu SP, Lin TS, Choi DW. Buckminsterfullerenol free radical scavengers reduce excitotoxic and apoptotic death of cultured cortical neurons. Neurobiol Dis. 1996;3:129-135.

16. Jin H, Chen WQ, Tang XW, et al. Polyhydroxylated C60, fullerenols, as glutamate receptor antagonists and neuroprotective agents. $J$ Neurosci Res. 2000;62:600-607.

17. Yan L, Zhao F, Li S, Hu Z, Zhao Y. Low-toxic and safe nanomaterials by surface-chemical design, carbon nanotubes, fullerenes, metallofullerenes, and graphenes. Nanoscale. 2011;3:362-382.

18. Yin S, Tang M, Su L, et al. Effects of epigallocatechin-3-gallate on lead-induced oxidative damage. Toxicology. 2008;249:45-54.

19. Fairbairn DW, Olive PL, O’Neill KL. The Comet assay: a comprehensive review. Mutat Res. 1995;339:37-59.

20. Adonaylo VN, Oteiza PI. Lead intoxication: antioxidant defenses and oxidative damage in rat brain. Toxicology. 1999;135:77-85.

21. Li X, Chen Z, Guo G, et al. Study on self-aggregation behavior of fullerenols in water. Journal of Instrumental Analysis. 2009;04: 432-435.

22. Beranova E, Klouda K, Vavra L, et al. Radioprotective properties and a toxicity test of $\mathrm{C} 60$ fullerene derivative in vivo and in vitro. Nanocon. 2010;10:12-14.

23. Bobylev AG, Marsaqishvili LG, Podlubnaia ZA. Fluorescence analysis of the action of soluble derivatives of fullerene C60 on amyloid fibrils of the brain peptide Abeta(1-42). Biofizika. 2010;55:780-784. Russian.

24. Brausch KA, Anderson TA, Smith PN, Maul JD. The effect of fullerenes and functionalized fullerenes on Daphnia magna phototaxis and swimming behavior. Environ Toxicol Chem. 2011;30:878-884.

25. Service RF. Nanotoxicology: nanotechnology grows up. Science. 2004;304:1732-1734.

26. Baker GL, Gupta A, Clark ML, et al. Inhalation toxicity and lung toxicokinetics of $\mathrm{C} 60$ fullerene nanoparticles and microparticles. Toxicol Sci. 2008;101:122-131.
International Journal of Nanomedicine

\section{Publish your work in this journal}

The International Journal of Nanomedicine is an international, peerreviewed journal focusing on the application of nanotechnology in diagnostics, therapeutics, and drug delivery systems throughou the biomedical field. This journal is indexed on PubMed Central,

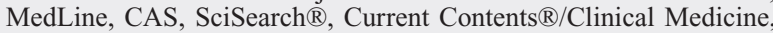

\section{Dovepress}

Journal Citation Reports/Science Edition, EMBase, Scopus and the Elsevier Bibliographic databases. The manuscript management system is completely online and includes a very quick and fair peer-review system, which is all easy to use. Visit http://www.dovepress.com/ testimonials.php to read real quotes from published authors. 